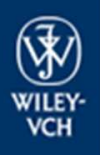

Particle \& Particle Systems

Characterization

\title{
Tunable Visible Emission of Luminescent Hybrid Nanoparticles Incorporating Two Complementary Luminophores: ZnO Nanocrystals and [Mo6Br14]2- Nanosized Cluster Units
}

\begin{tabular}{|c|c|}
\hline Journal: & Particle \& Particle Systems Characterization \\
\hline Manuscript ID: & ppsc. 201200047.R1 \\
\hline Wiley - Manuscript type: & Communication \\
\hline Date Submitted by the Author: & $\mathrm{n} / \mathrm{a}$ \\
\hline Complete List of Authors: & $\begin{array}{l}\text { AUBERT, Tangi; Université de Rennes 1, UMR } 6226 \\
\text { NERAMBOURG, Nicolas; Université de Rennes 1, UMR } 6226 \\
\text { SAITO, Noriko; NIMS, } \\
\text { HANEDA, Hajime; NIMS, } \\
\text { OHASHI, Naoki; NIMS, } \\
\text { MORTIER, Michel; CNRS-Paristech, } \\
\text { CORDIER, Stephane; Université de Rennes 1, UMR } 6226 \\
\text { GRASSET, Fabien; Université de Rennes 1, UMR } 6226\end{array}$ \\
\hline \multicolumn{2}{|l|}{ Free Keywords: } \\
\hline Abstract: & $\begin{array}{l}\text { We report the stabilization in presence of water of colloidal solutions } \\
\text { associating ZnO nanocrystals and [Mo6Br14]2- cluster units using } \\
\text { polyvinylpyrrolidone (PVP). The resulting ZnO-Cs2[Mo6Br14]@PVP } \\
\text { solutions were stable even in the presence of water and could be used for } \\
\text { the preparation of transparent and luminescent polymer thin films and } \\
\text { ZnO-Cs2[Mo6Br14]@SiO2 silica nanoparticles. This article presents the first } \\
\text { syntheses of luminescent functional thin films or silica nanoparticles based } \\
\text { on [Mo6X14]2-@ZnO hybrid. The nanomaterials have been fully } \\
\text { characterized by the means of FE-SEM, STEM, X-ray diffraction techniques, } \\
\text { dynamic light scattering, UV-Vis absorption and emission spectroscopies. } \\
\text { Luminescence experiments have shown that the intrinsic photophysical } \\
\text { properties of the cluster anion or ZnO nanocrystal are not affected by their } \\
\text { inclusion in PVP or silica matrix, even after several month of aging in water } \\
\text { solution. Therefore, we have shown that we could prepare versatile } \\
\text { luminescent nanomaterials with broad scale signal in the visible part. }\end{array}$ \\
\hline
\end{tabular}


DOI: $10.1002 /$ ppsc. 201200047

\section{Particle}

Submitted to

8 Particle Systems Characterization

Tunable Visible Emission of Luminescent Hybrid Nanoparticles Incorporating Two Complementary Luminophores: $\mathrm{ZnO}$ Nanocrystals and $\left[\mathrm{Mo}_{6} \mathrm{Br}_{14}\right]^{2-}$ Nanosized Cluster Units

Tangi Aubert ${ }^{\& \xi}$, Nicolas Nerambourg ${ }^{\&}, N_{\text {Noriko Saito }}$, Hajime Haneda ${ }^{\$}$, Naoki Ohashi ${ }^{\$}$,

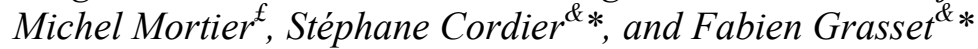

[\&] Dr. T. Aubert, Dr. N. Nerambourg, Dr. S. Cordier, Dr. F. Grasset

Université de Rennes 1, UMR Institut des Sciences Chimiques de Rennes UR1-CNRS 6226, Equipe Chimie du Solide et Matériaux, 263 av. du Général Leclerc, 35042 Rennes, France

[\$] Dr. N. Saito, Prof. H. Haneda, Dr. N. Ohashi

National Institute for Materials Science, 1-1 Namiki, Tsukuba, Ibaraki 305-044, Japan

[£] Dr. Michel Mortier

Ecole Nationale Supérieure de Chimie de Paris, ENSCP, 11 rue Pierre et Marie Curie, 75005 Paris, France

[§] Present address: Ghent University, Department of Inorganic and Physical Chemistry, Physics and Chemistry of Nanostructures group, Krijgslaan 281-S3, 9000 Gent, Belgium

* E-mail: tangi.aubert@ugent.be, fabien.grasset@univ-rennes1.fr, stephane.cordier@univrennes1.fr

Keywords: metal atom clusters; silica nanoparticles; tunable luminescence; $\mathrm{ZnO}$ nanocrystals

Luminescent silica nanoparticles have numerous applications in the fields of biotechnologies ${ }^{[1,2]}$ or photonics. ${ }^{[3,4]}$ They are usually achieved through the encapsulation in a silica matrix of a luminophore such as organic dyes, ${ }^{[5-8]}$ semi-conductor quantum dots, ${ }^{[9-13]}$ organometallic complexes ${ }^{[14-17]}$ or rare-earth-doped nanocrystals. ${ }^{[18-20]}$ Most of these materials are limited to single narrow emission properties. However, the increasing complexity of the applications of nanomaterials in the fields of photonic or light emitting devices requires materials with always more sophisticated emission properties. In particular, the achievement of materials with tunable and broad emission properties is of major interest for the field of photonics and for the manipulation of light over a large spectral range. In this frame, Zhou et al. reported materials with tunable and broad emission properties by stabilizing multivalent bismuth nanocrystals in a porous silica matrix. ${ }^{[21]}$ With their approach, they realized 
Submitted to

macrosized glass chips exhibiting blue-green, orange, red or white emission depending on the excitation wavelength.

We present here the synthesis and characterization of materials based on silica nanoparticles incorporating two kinds of luminophores namely $\mathrm{ZnO}$ nanocrystals and $\left[\mathrm{Mo}_{6} \mathrm{Br}_{14}\right]^{2-}$ cluster units. Interestingly, $\mathrm{ZnO}$ nanocrystals and nanosized $\left[\mathrm{Mo}_{6} \mathrm{Br}^{\mathrm{i}} \mathrm{Br}^{\mathrm{a}}{ }_{6}\right]^{2-}$ units are two luminophores which exhibit complementary emission properties. $\mathrm{ZnO}$ is a semiconductor material with a large energy gap between the conduction and valence bands $(3.37$ $\mathrm{eV}$. Regardless to their bulk or nanosized forms, $\mathrm{ZnO}$ materials show an excitonic UV emission under UV irradiation related to the energy band gap of the electronic structure. In addition to the latter emission, $\mathrm{ZnO}$ nanocrystals often show a supplementary large emission band (from 500 to $700 \mathrm{~nm}$ ) generally centered between 550 and $600 \mathrm{~nm}$. This visible emission known as trap emission, originates from defects located at the surface of the $\mathrm{ZnO}$ nanocrystals and more precisely from oxygen vacancies. ${ }^{[22,23]}$ On the other hand, under UV or visible excitation, $\left[\mathrm{Mo}_{6} \mathrm{Br}_{14}\right]^{2-}$ cluster units exhibit a broad emission window from 550 to $900 \mathrm{~nm}$ centred around $780 \mathrm{~nm} \cdot{ }^{[24]}\left[\mathrm{Mo}_{6} \mathrm{X}_{8}^{\mathrm{i}} \mathrm{X}_{6}^{\mathrm{a}}\right]^{2-}$ nanosized cluster units are built up from an octahedral $\mathrm{Mo}_{6}$ cluster bonded to eight inner face-capping ligands $\left(\mathrm{X}^{\mathrm{i}}, \mathrm{i}=\right.$ inner $)$ and to six bromine apical ligands $\left(\mathrm{X}^{\mathrm{a}}, \mathrm{a}=\right.$ apical $)$ located in terminal positions. $\left[\mathrm{Mo}_{6} \mathrm{X}_{8}^{\mathrm{i}} \mathrm{X}_{6}^{\mathrm{a}}\right]^{2-}(\mathrm{X}=\mathrm{Cl}$, $\mathrm{Br}$ and I) are associated with inorganic or organic cations in many compounds of general formula $\mathrm{A}_{2}\left[\mathrm{Mo}_{6} \mathrm{X}_{8}^{\mathrm{i}} \mathrm{X}_{6}^{\mathrm{a}}\right]\left(\mathrm{A}=\right.$ alkali cation, quaternary ammonium, $\left.\mathrm{H}_{3} \mathrm{O}^{+} \ldots\right)$ prepared either by solid state chemistry or by combined use of solid state and solution chemistries. $\mathrm{A}_{2}\left[\mathrm{Mo}_{6} \mathrm{X}_{8}^{\mathrm{i}} \mathrm{X}_{6}^{\mathrm{a}}\right]$ series afford thus useful $\left[\mathrm{Mo}_{6} \mathrm{X}_{8}^{\mathrm{i}} \mathrm{X}_{6}^{\mathrm{a}}\right]^{2-}$ building blocks with specific physicochemical properties that can be involved in the preparation of molecular assemblies and nanomaterials (e.g.: dendrimers, liquid crystal and polymer nanocomposites, functional surfaces). ${ }^{[25-34]}$ 


\section{Particle}

Submitted to \& Particle Systems Characterization

In a previous work we showed that the association of $\mathrm{ZnO}$ nanocrystals and $\mathrm{Mo}_{6}$-based cluster units lead to colloidal materials with unique tunable emission properties. ${ }^{[35]}$ Depending on the excitation wavelength, the resulting cluster@ZnO hybrid nanoparticles showed either the visible emission of $\mathrm{ZnO}$ or the emission of the clusters, or even a combination of both of them, resulting in a broad emission covering almost all the visible range of light. Besides visible emission upon irradiation, clusters are known to generate singlet oxygen ${ }^{[36]}$ whilst single $\mathrm{ZnO}$ nanocrystals can generate second order $\mathrm{NLO}^{[37]}$ Indeed, the targeted hybrid cluster@ZnO nanoparticles should afford promising multifunctional materials with potential applications in nanobiotechnology, in photodynamic therapy (PDT) or nonlinear optical (NLO) bioimaging. Before applications, the stabilisation and dispersion of cluster@ $\mathrm{ZnO}$ nanoparticles in stable organic or inorganic matrix constitutes a mandatory step. A straightforward strategy to obtain a homogeneous and stable material is the embedding of the cluster@ZnO nanoparticles in silica matrix. This technique is well known for providing nanomaterials with enhanced colloidal and physico-chemical stability as well as biocompatibility. ${ }^{[38]}$ The encapsulation of cluster units based on $\mathrm{Mo}_{6}$ and $\operatorname{Re}_{6}$ clusters in silica nanoparticles has already been demonstrated in the past few years. ${ }^{[39-41]}$ The cluster embedding in silica matrix efficiently decreases quenching phenomena that alter the cluster luminescence properties in solution. ${ }^{[40]}$ The latter usually results from the presence of dissolved oxygen. ${ }^{[36]}$ If the $\mathrm{Mo}_{6}$ cluster solution chemistry is compatible with silica formation reactions, this is not true for the solution chemistry of $\mathrm{ZnO}$ nanocrystals. This feature makes the encapsulation of $\mathrm{ZnO}$ nanocrystals in a silica matrix much trickier than that of $\left[\mathrm{Mo}_{6} \mathrm{Br}_{14}\right]^{2-}$ cluster units. Indeed, $\mathrm{ZnO}$ nanocrystals hardly stand the presence of water, an essential reactant for the sol-gel chemistry of silica, which provokes their aggregation. In addition, the traditional processes for the synthesis of spherical and monodisperse silica particles such as the Stöber process usually requires high $\mathrm{pH}$ values. ${ }^{[42]}$ This is in contradiction with the 
Submitted to \& Particle Systems Characterization

stability of $\mathrm{ZnO}$ nanocrystals that dissolve for $\mathrm{pH}$ value higher than 9. It explains why the references dealing with the preparation of $\mathrm{ZnO} @ \mathrm{SiO}_{2}$ nanoparticles are scarce. Tang et al. ${ }^{[43]}$ reported the preparation of such nanoparticles through a modified Stöber process, resulting in materials whose emission properties depend on the precipitation $\mathrm{pH}$ value of the $\mathrm{ZnO}$ nanocrystals. On the other hand, Wang et al. ${ }^{[44]}$ reported the preparation of $\mathrm{ZnO} @ \mathrm{SiO}_{2}$ through a water-in-oil microemulsion process, but they did not study the luminescence properties of their materials. The stabilization of $\mathrm{ZnO}$ nanocrystals in aqueous solutions has been reported through their functionalization with polymers, ${ }^{[45,46]}$ organic ligands ${ }^{[47]}$ or even organosilanes. ${ }^{[48,49]}$

We report here the stabilization in presence of water of colloidal solutions associating $\mathrm{ZnO}$ nanocrystals and $\left[\mathrm{Mo}_{6} \mathrm{Br}_{14}\right]^{2-}$ cluster units using polyvinylpyrrolidone $\left(\mathrm{PVP} ; \mathrm{M}_{\mathrm{w}}=40000 \mathrm{~g}\right.$ $\mathrm{mol}^{-1}$ ) as stabiliser, which is a widely used capping agent. ${ }^{[50]}$ The resulting $\mathrm{ZnO}$ $\mathrm{Cs}_{2}\left[\mathrm{Mo}_{6} \mathrm{Br}_{14}\right] @$ PVP colloidal solutions were stable even in the presence of water and could be therefore used for the preparation of transparent and luminescent polymer thin films and $\mathrm{ZnO}-\mathrm{Cs}_{2}\left[\mathrm{Mo}_{6} \mathrm{Br}_{14}\right] @ \mathrm{SiO}_{2}$ silica nanoparticles. The thin films were prepared by dip-coating in the $\mathrm{ZnO}-\mathrm{Cs}_{2}\left[\mathrm{Mo}_{6} \mathrm{Br}_{14}\right] @ \mathrm{PVP}$ solutions and were characterized by field-emission scanning electron microscopy (FE-SEM) and luminescence spectrometry. $\mathrm{ZnO}-\mathrm{Cs}_{2}\left[\mathrm{Mo}_{6} \mathrm{Br}_{14}\right] @ \mathrm{SiO}_{2}$ silica nanoparticles were obtained by the concomitant encapsulation of the two luminophores $\mathrm{ZnO}$ nanocrystals and $\left[\mathrm{Mo}_{6} \mathrm{Br}_{14}\right]^{2-}$ cluster units in silica nanoparticles through a modified

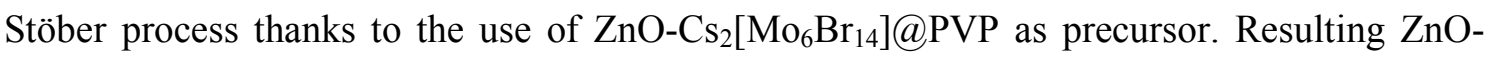
$\mathrm{Cs}_{2}\left[\mathrm{Mo}_{6} \mathrm{Br}_{14}\right] @ \mathrm{SiO}_{2}$ nanoparticles were characterized by scanning transmission electron microscope (STEM), luminescence spectroscopy and X-ray diffraction (XRD). Both the films and the nanoparticles exhibited tunable luminescence properties as their emission spectra depended on the excitation wavelength. In addition, it is worth noting that the luminescence 


\section{Particle}

Submitted to \& Particle Systems Characterization properties of $\mathrm{ZnO}-\mathrm{Cs}_{2}\left[\mathrm{Mo}_{6} \mathrm{Br}_{14}\right] @ \mathrm{SiO}_{2}$ nanoparticles are stable in water solution even after 3 months of ageing.

The $\mathrm{Cs}_{2}\left[\mathrm{Mo}_{6} \mathrm{Br}_{14}\right]$ cluster compound was synthesized by solid state chemistry at high temperature, according to an already published procedure. ${ }^{[51]}$

The $\mathrm{ZnO}$ colloid was synthesized by a sol-gel route as described in the experimental section and adapted from a previously reported procedure. ${ }^{[52,53]}$ The obtained $\mathrm{ZnO}$ colloidal solution consisted of $5 \mathrm{~nm}$ sized nanocrystals (see Supporting Information for dynamic light scattering measurements and transmission electron microscopy images). The $\mathrm{ZnO}$ concentration of the colloidal solution after purification was $0.5 \mathrm{M}$, as determined by inductively coupled plasma optical emission spectrometry (ICP-OES) measurements.

The colloidal solution of clusters and $\mathrm{ZnO}$ nanocrystals was prepared by dissolving $70 \mathrm{mg}$ of $\mathrm{Cs}_{2}\left[\mathrm{Mo}_{6} \mathrm{Br}_{14}\right]$ in a mixture of $5 \mathrm{ml}$ of ethanol and $1 \mathrm{ml}$ of distilled water. Then, $2 \mathrm{~g}$ of PVP $\left(\mathrm{M}_{\mathrm{w}}=40000 \mathrm{~g} \mathrm{~mol}^{-1}\right)$ were dissolved in the resulting cluster sol. Finally, $5 \mathrm{ml}$ of the $\mathrm{ZnO}$ colloidal solution in ethanol were added to the mixture. Thus, in this procedure, the $\mathrm{ZnO}$ nanocrystals could be stabilized in the presence of water after prior synthesis and purification of the $\mathrm{ZnO}$ colloids and further addition in a PVP solution. Indeed, if introduced during the synthesis of $\mathrm{ZnO}$, the PVP could decrease the surface defects of the nanocrystals resulting in the loss of the visible emission. ${ }^{[54]}$

From the stabilised colloidal solution, denoted $\mathrm{ZnO}-\mathrm{Cs}_{2}\left[\mathrm{Mo}_{6} \mathrm{Br}_{14}\right] @ \mathrm{PVP}$, films were deposited on soda lime glass slides by dip-coating. The above mentioned $\mathrm{ZnO}-$ $\mathrm{Cs}_{2}\left[\mathrm{Mo}_{6} \mathrm{Br}_{14}\right] @ \mathrm{PVP}$ solution was placed in a Teflon ${ }^{\circledR}$ container and the substrate was introduced in the solution. After one minute of immersion, the substrate was pulled up at 200 $\mathrm{mm} \min ^{-1}$. After deposition, the films were dried at room temperature. According to the quantities of precursors introduced in the synthesis, the composition of the films after complete evaporation of the solvent was $88.0 \mathrm{wt} \%$ of PVP, $8.9 \mathrm{wt} \%$ of $\mathrm{ZnO}$ and $3.1 \mathrm{wt} \%$ of 


\section{Particle}

Submitted to \& Particle Systems Characterization

$\mathrm{Cs}_{2}\left[\mathrm{Mo}_{6} \mathrm{Br}_{14}\right]$. These films are denoted as $\left[\mathrm{ZnO}_{-} \mathrm{Cs}_{2}\left[\mathrm{Mo}_{6} \mathrm{Br}_{14}\right] \text { @PVP }\right]_{\text {film. The homogeneity }}$ and the thickness of the $\left[\mathrm{ZnO}-\mathrm{Cs}_{2}\left[\mathrm{Mo}_{6} \mathrm{Br}_{14}\right] @ \mathrm{PVP}\right]_{\text {film }}$ have been determined by FE-SEM. The cross section of the material was observed after breaking the slide in the direction of the pulling up axe (i.e. longitudinal section). The FE-SEM image on Figure 1 illustrates a perfectly homogeneous film with an average thickness of $3 \mu \mathrm{m}$. Additional experiments showed that the thickness of the film could easily be controlled by varying the pulling speed or the viscosity (i.e. concentration of PVP) of the solution, up to $7 \mu \mathrm{m}$ thick films. These films are transparent in the visible range and luminescent under UV excitation $(365 \mathrm{~nm}, 4$ watt lamp) (Figure 1). For an excitation wavelength of $325 \mathrm{~nm}$, the emission properties of the $\left[\mathrm{ZnO}-\mathrm{Cs}_{2}\left[\mathrm{Mo}_{6} \mathrm{Br}_{14}\right] @ \mathrm{PVP}\right]_{\text {film }}$ produced a large emission band covering almost all the visible range (see Supporting Information Figure S8).

The $\mathrm{ZnO}-\mathrm{Cs}_{2}\left[\mathrm{Mo}_{6} \mathrm{Br}_{14}\right] @ \mathrm{SiO}_{2}$ nanoparticles were synthesized through a modified Stöber process, using TMAOH as the base instead of the classical ammonia solution. In a synthesis, $1 \mathrm{ml}$ of the above mentioned $\mathrm{ZnO}-\mathrm{Cs}_{2}\left[\mathrm{Mo}_{6} \mathrm{Br}_{14}\right] @ \mathrm{PVP}$ solution was diluted in $19 \mathrm{ml}$ of ethanol and $1 \mathrm{ml}$ of distilled water. Then, $0.05 \mathrm{ml}$ of TMAOH and $1 \mathrm{ml}$ of TEOS were added to the solution and the reaction was left under stirring for 4 days. Finally the nanoparticles were collected by centrifugation and washed several times with ethanol. In our process, the use of TMAOH instead of ammonia for the base-catalyzed condensation of the silica matrix appeared to be essential. Indeed, all attempts to use ammonia leaded to a loss of the visible emission of $\mathrm{ZnO}$. However, it was possible to form a thin shell of silica around the $\mathrm{ZnO}$ nanocrystals using TMAOH and then add ammonia for further growth of bigger silica nanoparticles. In these conditions, the visible emission of $\mathrm{ZnO}$ was preserved after purification and dispersion of the nanoparticles in ethanol, but then the emission always disappeared when drying the nanoparticles. In this latter case the visible emission of $\mathrm{ZnO}$ disappeared in about 24 hours after drying the nanoparticles, whereas for $\mathrm{ZnO}$ - 
Submitted to \& Particle Systems Characterization $\mathrm{Cs}_{2}\left[\mathrm{Mo}_{6} \mathrm{Br}_{14}\right] @ \mathrm{SiO}_{2}$ nanoparticles prepared by using only TMAOH as the base, they remained luminescent even when they were dried or dispersed in water. These observations might be related to the size of the cation balancing the charge of the silica matrix, which are $\mathrm{NH}_{3}{ }^{+}$or $\left(\mathrm{CH}_{3}\right)_{4} \mathrm{~N}^{+}$when using ammonia or TMAOH respectively. Smaller cations will produce silica with higher density, and if the density of the silica matrix at the vicinity of the $\mathrm{ZnO}$ nanocrystals is too high it might passivate its surface, resulting in a loss of the trap emission. Moreover, drying the nanoparticles can also provoke an additional densification of the silica matrix, explaining why the loss of the visible emission $\mathrm{ZnO}$ only appeared after drying the $\mathrm{ZnO}-\mathrm{Cs}_{2}\left[\mathrm{Mo}_{6} \mathrm{Br}_{14}\right] @ \mathrm{SiO}_{2}$ nanoparticles when using ammonia.

The $\mathrm{ZnO}-\mathrm{Cs}_{2}\left[\mathrm{Mo}_{6} \mathrm{Br}_{14}\right] @ \mathrm{SiO}_{2}$ nanoparticles were observed by STEM. The images on Figure 2 evidence the presence of $\mathrm{ZnO}$ nanocrystals inside the silica matrix. Additional XRD measurements performed on the powder (Supporting Information Figure S9) confirmed the presence of crystalline $\mathrm{ZnO}$ which was not dissolved during the base-catalyzed encapsulation process. The images in Figure 2 show that the sample consists in vermicular aggregates of $\mathrm{ZnO}-\mathrm{Cs}_{2}\left[\mathrm{Mo}_{6} \mathrm{Br}_{14}\right] @ \mathrm{SiO}_{2}$ nanoparticles. The diameter of the primary nanoparticles is roughly below $30 \mathrm{~nm}$. This aggregation state is explained by the low $\mathrm{pH}$ value -lower than 9- used for the synthesis of the silica matrix.

The luminescence properties of the $\mathrm{ZnO}-\mathrm{Cs}_{2}\left[\mathrm{Mo}_{6} \mathrm{Br}_{14}\right] @ \mathrm{SiO}_{2}$ nanoparticles were carefully investigated on solid state. The emission spectra of the nanoparticles depending on the excitation wavelength are reported on Figure 3. These spectra highlight the tunable character of the emission of these nanoparticles. For an excitation wavelength of $340 \mathrm{~nm}$, the trap emission of $\mathrm{ZnO}$ centered at $575 \mathrm{~nm}$ was predominant and masked the emission of the clusters. For an excitation wavelength of $450 \mathrm{~nm}$, the $\mathrm{ZnO}$ nanocrystals do not emit anymore and the nanoparticles produced the red emission of the $\left[\mathrm{Mo}_{6} \mathrm{Br}_{14}\right]^{2-}$ cluster units as already observed for $\mathrm{Cs}_{2}\left[\mathrm{Mo}_{6} \mathrm{Br}_{14}\right] @ \mathrm{SiO}_{2}$ nanoparticles. ${ }^{[39,55]}$ For an excitation wavelength of $365 \mathrm{~nm}$, 


\section{Particle}

Submitted to \& Particle Systems Characterization

the nanoparticles produced a large emission band covering almost all the visible range as found earlier for $\left(\left(\mathrm{n}-\mathrm{C}_{4} \mathrm{H}_{9}\right)_{4} \mathrm{~N}\right)_{2} \mathrm{Mo}_{6} \mathrm{Br}_{14} @ \mathrm{ZnO}$ colloidal solutions and nanopowders. The color coordiantes of these emission spectra have calculated and are represented in a chromaticity diagram in supporting information (Figure S10). Owing to the silica matrix, the $\mathrm{ZnO}-\mathrm{Cs}_{2}\left[\mathrm{Mo}_{6} \mathrm{Br}_{14}\right] @ \mathrm{SiO}_{2}$ nanoparticles are more stable than $\left(\left(\mathrm{n}-\mathrm{C}_{4} \mathrm{H}_{9}\right)_{4} \mathrm{~N}\right)_{2}\left[\mathrm{Mo}_{6} \mathrm{Br}_{14}\right] @ \mathrm{ZnO}$ colloids. Indeed, $\left(\left(\mathrm{n}-\mathrm{C}_{4} \mathrm{H}_{9}\right)_{4} \mathrm{~N}\right)_{2}\left[\mathrm{Mo}_{6} \mathrm{Br}_{14}\right] @ \mathrm{ZnO}$ nanoparticles are stable only in organic media and the luminescence of the cluster units is quenched by oxygen. A major finding of the present work is that the luminescence of the $\mathrm{ZnO}-\mathrm{Cs}_{2}\left[\mathrm{Mo}_{6} \mathrm{Br}_{14}\right] @ \mathrm{SiO}_{2}$ nanoparticles is preserved when dispersed in water, even after several months of aging. This is illustrated in Figure 3 which shows photography under a UV lamp of an aqueous solution of dispersed $\mathrm{ZnO}-\mathrm{Cs}_{2}\left[\mathrm{Mo}_{6} \mathrm{Br}_{14}\right] @ \mathrm{SiO}_{2}$ nanoparticles after three months of storage. The relatively equal contributions of the $\mathrm{ZnO}$ and of the clusters in the emission of the nanoparticles for an excitation of $365 \mathrm{~nm}$ result from an appropriate ratio between these two luminophores, which in this case was about $70\left(\mathrm{ZnO} / \mathrm{Cs}_{2}\left[\mathrm{Mo}_{6} \mathrm{Br}_{14}\right]\right.$ molar ratio). The excitation wavelength at which a broad emission is obtained can therefore be tuned by varying the respective proportions of $\mathrm{ZnO}$ and clusters.

In order to study the luminescence properties of the $\left[\mathrm{Mo}_{6} \mathrm{Br}_{14}\right]^{2-}$ cluster units and the $\mathrm{ZnO}$ nanocrystals within the silica matrix, time-resolved photoluminescence experiments were carried out at room temperature on $\mathrm{ZnO}-\mathrm{Cs}_{2}\left[\mathrm{Mo}_{6} \mathrm{Br}_{14}\right] @ \mathrm{SiO}_{2}$ powders. Lifetime measurements on $\mathrm{Cs}_{2}\left[\mathrm{Mo}_{6} \mathrm{Br}_{14}\right] @ \mathrm{SiO}_{2}$ nanoparticles were previously reported. ${ }^{[39]}$ The results are summarized in Table 1. For each experiment, excepted for $\mathrm{Cs}_{2}\left[\mathrm{Mo}_{6} \mathrm{Br}_{14}\right] @ \mathrm{SiO}_{2}$, three lifetimes were obtained.

For each excitation wavelength $\left(\lambda_{\mathrm{exc}}=380\right.$ and $\left.450 \mathrm{~nm}\right)$, the photoluminescence spectra of the $\mathrm{ZnO}-\mathrm{Cs}_{2}\left[\mathrm{Mo}_{6} \mathrm{Br}_{14}\right] @ \mathrm{SiO}_{2}$ nanoparticles were deconvoluted in order to distinguish the respective contribution of the two different luminophores. Indeed, for $\lambda_{\mathrm{exc}}=380 \mathrm{~nm}$ both $\mathrm{ZnO}$ 
Submitted to \& Particle Systems Characterization

nanocrystals and $\left[\mathrm{Mo}_{6} \mathrm{Br}_{14}\right]^{2-}$ cluster units contribute to the emission at $550 \mathrm{~nm}$ (supporting information Figure S11). Thus, for $\lambda_{\mathrm{exc}}=380 \mathrm{~nm}$ and $\lambda_{\mathrm{obs}}=550 \mathrm{~nm}$, we expected to find a long lifetime related to the cluster units and a short lifetime related to the $\mathrm{ZnO}$ nanocrystals. The longest lifetime obtained in these conditions $(26.67 \mu \mathrm{s})$ with a relatively weak amplitude is consequently attributed to the emission of the $\left[\mathrm{Mo}_{6} \mathrm{Br}_{14}\right]^{2-}$ cluster units. Regarding the lifetime of $2.83 \mu \mathrm{s}$, this value is in good agreement with that previously reported for the $\mathrm{ZnO}$ visible emission signal. ${ }^{[23]}$ Then, the shortest lifetime value $(0.95 \mu \mathrm{s})$ which corresponds to the largest contribution might be attributed to energy transfers between $\mathrm{ZnO}$ nanocrystals and the silica matrix or between $\mathrm{ZnO}$ nanocrystals and the cluster units.

For $\lambda_{\text {exc }}=450 \mathrm{~nm}$, only the cluster units contribute to the emission at $725 \mathrm{~nm}$. The deconvolution of the emission spectrum of the $\left[\mathrm{Mo}_{6} \mathrm{Br}_{14}\right]^{2-}$ cluster units $\left(\lambda_{\mathrm{exc}}=450 \mathrm{~nm}\right)$ shows two distinct emission bands (see supporting information Figure S12) corresponding to different excited states as previously reported in the literature. ${ }^{[56]}$ The main band centered at $700 \mathrm{~nm}$ is related to the longest $(58.14 \mu \mathrm{s})$ and the shortest $(1.91 \mu \mathrm{s})$ lifetimes obtained in these conditions. Very similar results were obtained in a previous work concerning the photoluminescence study of $\mathrm{Cs}_{2}\left[\mathrm{Mo}_{6} \mathrm{Br}_{14}\right] @ \mathrm{SiO}_{2}$ nanoparticles. ${ }^{[39]}$ The longest lifetime of $58.14 \mu \mathrm{s}$ is thus attributed to the phosphorescence of the $\left[\mathrm{Mo}_{6} \mathrm{Br}_{14}\right]^{2-}$ cluster units and the shortest one might be attributed to energy transfers between cluster units themselves or between cluster units and the silica matrix. The lifetime value of $14.3 \mu$ s also obtained in these conditions $\left(\lambda_{\mathrm{exc}}=450 \mathrm{~nm}\right.$ and $\left.\lambda_{\mathrm{obs}}=725 \mathrm{~nm}\right)$ can be consequently attributed to the second excited state (emission band centered at $786 \mathrm{~nm}$ ) involved in the photoluminescence electronic transitions. This value was not measured previously ${ }^{[39]}$ because this second excited state did not contributed at all in the emission at the observed wavelength $\left(\lambda_{\mathrm{obs}}=670 \mathrm{~nm}\right)$. The nature of the different electronic states involved in the photoluminescence process will be investigated in a future study. 
Submitted to \& Particle Systems Characterization

In conclusion, we successfully stabilized the $\mathrm{ZnO}$ nanocrystals in presence of water using PVP for their further co-encapsulation along with $\left[\mathrm{Mo}_{6} \mathrm{Br}_{14}\right]^{2-}$ cluster units in silica to form $\mathrm{ZnO}-\mathrm{Cs}_{2}\left[\mathrm{Mo}_{6} \mathrm{Br}_{14}\right] @ \mathrm{SiO}_{2}$ nanoparticles through a modified Stöber process. ZnO$\mathrm{Cs}_{2}\left[\mathrm{Mo}_{6} \mathrm{Br}_{14}\right] @ \mathrm{SiO}_{2}$ nanoparticles exhibit tunable emission properties with a broad emission spectrum covering almost all the visible range for an excitation wavelength of $365 \mathrm{~nm}$. Moreover, an important feature is that the luminescence properties are kept intact when the nanoparticles are dispersed in water. Hence, these nanoparticles are suitable for applications in aqueous media such as luminescent markers for bioimaging. Although the morphology of the nanoparticles (sphericity and monodispersity) needs to be improved for their integration in optical devices such as photonic crystals, the materials reported here can already find applications in white light emitting devices, in particular when associated with a blue lightemitting diode. ${ }^{[57]}$

\section{Experimental Section}

$\mathrm{ZnO}$ colloidal solution: For the synthesis of the $\mathrm{ZnO}$ colloidal solution, $\mathrm{Zn}(\mathrm{Ac})_{2} \cdot \mathrm{H}_{2} \mathrm{O}(4.39 \mathrm{~g})$ was suspended in $n$-propanol $(40 \mathrm{ml})$. The mixture was then heated at $125^{\circ} \mathrm{C}$ for 5 minutes using a rotary evaporator under ambient atmosphere and resulting in the evaporation of about $9 \mathrm{ml}$ of the solvent. While the solution was still warm $\left(\sim 60^{\circ} \mathrm{C}\right)$, TMAOH $(9 \mathrm{ml}, 25 \%$ in methanol) was added and the mixture was vigorously shacked until a perfectly clear solution was obtained. This $\mathrm{ZnO}$ colloidal solution was left under magnetic stirring overnight. In order to remove unreacted species, the nanocrystals were further purified by precipitation with heptane (1:2 volume ratio between $\mathrm{ZnO}$ solution and heptane) followed by centrifugation. Finally the collected nanocrystals were dispersed in ethanol $(20 \mathrm{ml})$.

Characterization techniques: FE-SEM images were performed with a JEOL JSM 6301F microscope operating at $7 \mathrm{kV}$. STEM images were performed using a Hitachi SU8000 
Submitted to \& Particle Systems Characterization

microscope operating at $30 \mathrm{kV}$. Photoluminescence spectra (Figure 3) were recorded using a Horiba Jobin Yvon FluoroLog spectrophotometer using a photomultiplier as detector.

Time-resolved photoluminescence: Time-resolved photoluminescence measurements were performed with a home-made setup using a CCD camera as detector. The kinetics parameters were determined by fitting the photoluminescence decays with the following equation: $y=$ $\mathrm{A}_{1} \mathrm{e}\left(-\mathrm{x} / \tau_{1}\right)+\mathrm{A}_{2} \mathrm{e}\left(-\mathrm{x} / \tau_{2}\right)+\mathrm{A}_{3} \mathrm{e}\left(-\mathrm{x} / \tau_{3}\right)$

\section{Supporting Information}

Supporting Information is available from the Wiley Online Library or from the author.

\section{Acknowledgements}

This work was supported by the University of Rennes 1, CNRS, ANR (Project CLUSTOP 2011 BS08 013 01), Région Bretagne and the Collège Doctoral Franco-Japonais. The authors thank K. Hasegawa (NIMS) for supplying the STEM images and J. Le Lannic (University of Rennes 1) for the FE-SEM images.

Received: ((will be filled in by the editorial staff))

Revised: ((will be filled in by the editorial staff)) Published online: ((will be filled in by the editorial staff))

[1] A. Burns, H. Ow, U. Wiesner, Chem. Soc. Rev. 2006, 35, 1028.

[2] A. Burns, J. Vider, H. Ow, E. Herz, O. Penate-Medina, M. Baumgart, S. M. Larson, U. Wiesner, M. Bradbury, Nano Lett. 2009, 9, 442.

[3] M. A. Noginov, G. Zhu, A. M. Belgrave, R. Bakker, V. M. Shalaev, E. E. Narimanov, S. Stout, E. Herz, T. Suteewong, U. Wiesner, Nature 2009, 460, 1110.

[4] J.-F. Dechézelles, T. Aubert, F. Grasset, S. Cordier, C. Barthou, C. Schwob, A. Maitre, R. A. L. Vallée, H. Cramail, S. Ravaine, PCCP 2010, 12, 11993.

[5] H. Giesche, E. Matijevic, Dyes Pig. 1991, 17, 323.

[6] A. van Blaaderen, A. Vrij, Langmuir 1992, 8, 2921.

[7] H. Ow, D. R. Larson, M. Srivastava, B. A. Baird, W. W. Webb, U. Wiesner, Nano Lett. $\mathbf{2 0 0 5}, 5,113$. 
[8] S. Santra, D. Dutta, B. M. Moudgil, Food Bioprod. Process. 2005, 83, 136.

[9] S.-Y. Chang, L. Liu, S. A. Asher, J. Am. Chem. Soc. 1994, 116, 6739.

[10] P. Mulvaney, L. M. Liz-Marzan, M. Giersig, T. Ung, J. Mater. Chem. 2000, 10, 1259.

[11] D. Gerion, F. Pinaud, S. C. Williams, W. J. Parak, D. Zanchet, S. Weiss, A. P.

Alivisatos, J. Phys. Chem. B 2001, 105, 8861.

[12] M. Darbandi, R. Thomann, T. Nann, Chem. Mater. 2005, 17, 5720.

[13] S. T. Selvan, T. T. Tan, J. Y. Ying, Adv. Mater. 2005, 17, 1620.

[14] S. Santra, P. Zhang, K. Wang, R. Tapec, W. Tan, Anal. Chem. 2001, 73, 4988.

[15] R. P. Bagwe, C. Yang, L. R. Hilliard, W. Tan, Langmuir 2004, 20, 8336.

[16] P. C. R. Soares-Santos, H. I. S. Nogueira, V. Félix, M. G. B. Drew, R. A. Sa Ferreira,

L. D. Carlos, T. Trindade, Chem. Mater. 2003, 15, 100.

[17] J. Yuan, G. Wang, TrAC, Trends Anal. Chem. 2006, 25, 490.

[18] Z. Li, Y. Zhang, Angew. Chem. Int. Ed. 2006, 45, 7732.

[19] S. Sivakumar, P. R. Diamente, F. C. J. M. van Veggel, Chem. Eur. J. 2006, 12, 5878.

[20] S. Nagarajan, Z. Li, V. Marchi-Artzner, F. Grasset, Y. Zhang, Med. Biol. Eng. Comput. 2010, 48, 1033.

[21] S. Zhou, N. Jiang, B. Zhu, H. Yang, S. Ye, G. Lakshminarayana, J. Hao, J. Qiu, Adv. Funct. Mater. 2008, 18, 1407.

[22] A. van Dijken, E. A. Meulenkamp, D. Vanmaekelbergh, A. Meijerink, J. Phys. Chem. B 2000, 104, 1715.

[23] M. L. Kahn, T. Cardinal, B. Bousquet, M. Monge, V. Jubera, B. Chaudret, ChemPhysChem 2006, 7, 2392.

[24] A. W. Maverick, J. S. Najdzionek, D. MacKenzie, D. G. Nocera, H. B. Gray, J. Am. Chem. Soc. 1983, 105, 1878. 
[25] S. Cordier, K. Kirakci, D. Méry, C. Perrin, D. Astruc, Inorg. Chim. Acta 2006, 359, 1705.

[26] W. C. Dorman, R. E. McCarley, Inorg. Chem. 1974, 13, 491.

[27] L. F. Szczepura, K. A. Ketcham, B. A. Ooro, J. A. Edwards, J. N. Templeton, D. L. Cedeño, A. J. Jircitano, Inorg. Chem. 2008, 47, 7271.

[28] J. H. Golden, H. Deng, F. J. DiSalvoa, J. M. J. Fréchet, P. M. Thompson, Science 1995, $268,1463$.

[29] G. Prabusankar, Y. Molard, S. Cordier, S. Golhen, Y. L. Gal, C. Perrin, L. Ouahab, S. Kahlal, J.-F. Halet, Eur. J. Inorg. Chem. 2009, 2153.

[30] D. Méry, L. Plault, S. Nlate, D. Astruc, S. Cordier, K. Kirakci, C. Perrin, Z. Anorg. Allg. Chem. 2005, 631, 2746.

[31] S. Ababou-Girard, S. Cordier, B. Fabre, Y. Molard, C. Perrin, ChemPhysChem 2007, $8,2086$.

[32] B. Fabre, S. Cordier, Y. Molard, C. Perrin, S. Ababou-Girard, C. Godet, J. Phys. Chem. C 2009, 113, 17437.

[33] Y. Molard, F. Dorson, V. Circu, T. Roisnel, F. Artzner, S. Cordier, Angew. Chem. Int. Ed. 2010, 49, 3351.

[34] A. S. Mocanu, M. Amela-Cortes, Y. Molard, V. Circu, S. Cordier, Chem. Commun. 2011, 47.

[35] F. Grasset, Y. Molard, S. Cordier, F. Dorson, M. Mortier, C. Perrin, M. Guilloux-Viry, T. Sasaki, H. Haneda, Adv. Mater. 2008, 20, 1710.

[36] J. A. Jackson, C. Turro, M. D. Newsham, D. G. Nocera, J. Phys. Chem. 1990, 94, 4500.

[37] R. Le Dantec, Y. Mugnier, G. Djanta, L. Bonacina, J. r. m. Extermann, L. Badie, C. Joulaud, M. Gerrmann, D. Rytz, J. P. Wolf, C. Galez, J. Phys. Chem. C 2011, 115, 15140. 
[38] A. Guerrero-Martínez, J. Pérez-Juste, L. M. Liz-Marzán, Adv. Mater. 2010, 22, 1182.

[39] F. Grasset, F. Dorson, S. Cordier, Y. Molard, C. Perrin, A. M. Marie, T. Sasaki, H.

Haneda, Y. Bando, M. Mortier, Adv. Mater. 2008, 20, 143.

[40] T. Aubert, A. Y. Ledneva, F. Grasset, K. Kimoto, N. G. Naumov, Y. Molard, N. Saito, H. Haneda, S. Cordier, Langmuir 2010, 26, 18512.

[41] T. Aubert, F. Grasset, S. Mornet, E. Duguet, O. Cador, S. Cordier, Y. Molard, V.

Demange, M. Mortier, H. Haneda, J. Colloid Interface Sci. 2010, 341, 201.

[42] W. Stöber, A. Fink, E. Bohn, J. Colloid Interface Sci. 1968, 26, 62.

[43] X. Tang, E. S. G. Choo, L. Li, J. Ding, J. Xue, Chem. Mater. 2010, 22, 3383.

[44] J. Wang, T. Tsuzuki, L. Sun, X. Wang, ACS Appl. Mater. Interfaces 2010, 2, 957.

[45] H.-M. Xiong, J. Mater. Chem. 2010, 20, 4251.

[46] S. Saliba, C. Valverde Serrano, J. Keilitz, M. L. Kahn, C. Mingotaud, R. Haag, J.-D. Marty, Chem. Mater. 2010, 22, 6301.

[47] Y.-S. Fu, X.-W. Du, S. A. Kulinich, J.-S. Qiu, W.-J. Qin, R. Li, J. Sun, J. Liu, J. Am. Chem. Soc. 2007, 129, 16029.

[48] R.-O. Moussodia, L. Balan, R. Schneider, New J. Chem. 2008, 32, 1388.

[49] R.-O. Moussodia, L. Balan, C. Merlin, C. Mustin, R. Schneider, J. Mater. Chem. 2010, $20,1147$.

[50] C. Graf, D. L. J. Vossen, A. Imhof, A. van Blaaderen, Langmuir 2003, 19, 6693.

[51] K. Kirakci, S. Cordier, C. Perrin, Z. Anorg. Allg. Chem. 2005, 631, 411.

[52] F. Grasset, S. Cordier, Y. Molard, C. Perrin, V. Nazabal, M. Guilloux-Viry, S. Pechev, N. Saito, H. Ryoken, H. Haneda, T. Sasaki, Int. J. Nanotechnol. 2008, 5, 708.

[53] T. Aubert, F. Grasset, M. Potel, V. Nazabal, T. Cardinal, S. Pechev, N. Saito, N. Ohashi, H. Haneda, Sci. Technol. Adv. Mat. 2010, 11, 044401. 
[54] L. Guo, S. Yang, C. Yang, P. Yu, J. Wang, W. Ge, G. K. L. Wong, Chem. Mater. 2000, 12, 2268.

[55] F. Grasset, F. Dorson, Y. Molard, S. Cordier, V. Demange, C. Perrin, V. MarchiArtzner, H. Haneda, Chem. Commun. 2008, 4729.

[56] H. Miki, T. Ikeyama, Y. Sasaki, T. Azumi, J. Phys. Chem. 1992, 96, 3236.

[57] N. Ohashi, N. Ebisawa, T. Sekiguchi, I. Sakaguchi, Y. Wada, T. Takenaka, H. Haneda, Appl. Phys. Lett. 2005, 86, 091902. 


\section{List of figures and table}

Figure 1. Left: FE-SEM image of the cross section of a $\left[\mathrm{ZnO}-\mathrm{Cs}_{2}\left[\mathrm{Mo}_{6} \mathrm{Br}_{14}\right] @ \mathrm{PVP}\right]_{\text {film }}$ with an average thickness of $3 \mu \mathrm{m}$. Right: emission of a $\left[\mathrm{ZnO}-\mathrm{Cs}_{2}\left[\mathrm{Mo}_{6} \mathrm{Br}_{14}\right] @ \mathrm{PVP}\right]_{\text {film }}$ under a UV $\operatorname{lamp}\left(\lambda_{\mathrm{exc}}=365 \mathrm{~nm}\right)$.

Figure 2. STEM images of $\mathrm{ZnO}-\mathrm{Cs}_{2}\left[\mathrm{Mo}_{6} \mathrm{Br}_{14}\right] @ \mathrm{SiO}_{2}$ nanoparticles.

Figure 3. Left: normalized emission spectra of $\mathrm{ZnO}-\mathrm{Cs}_{2}\left[\mathrm{Mo}_{6} \mathrm{Br}_{14}\right] @ \mathrm{SiO}_{2}$ nanoparticles depending on the excitation wavelength. Right: emission of $\mathrm{ZnO}-\mathrm{Cs}_{2}\left[\mathrm{Mo}_{6} \mathrm{Br}_{14}\right] @ \mathrm{SiO}_{2}$ nanoparticles dispersed in water under UV lamp $\left(\lambda_{\mathrm{exc}}=365 \mathrm{~nm}\right)$.

Table 1. Photoluminescence lifetimes of $\mathrm{ZnO}-\mathrm{Cs}_{2}\left[\mathrm{Mo}_{6} \mathrm{Br}_{14}\right] @ \mathrm{SiO}_{2}$ and $\mathrm{Cs}_{2}\left[\mathrm{Mo}_{6} \mathrm{Br}_{14}\right] @ \mathrm{SiO}_{2}$ nanoparticles under solid state conditions. Experiments on $\mathrm{Cs}_{2}\left[\mathrm{Mo}_{6} \mathrm{Br}_{14}\right] @ \mathrm{SiO}_{2}$ nanoparticles were previously reported by our team. ${ }^{[39]}$ Kinetic parameters were obtained by fitting the luminescence decay curves with a three exponential equation (see experimental section).

\begin{tabular}{lcccccccc}
\hline & $\lambda_{\text {exc }}[\mathrm{nm}]$ & $\lambda_{\text {obs }}[\mathrm{nm}]$ & $\tau_{1}[\mu \mathrm{s}]$ & $\mathrm{A}_{1}$ & $\tau_{2}[\mu \mathrm{s}]$ & $\mathrm{A}_{2}$ & $\tau_{3}[\mu \mathrm{s}]$ & $\mathrm{A}_{3}$ \\
\hline $\mathrm{ZnO}-\mathrm{Cs}_{2}\left[\mathrm{Mo}_{6} \mathrm{Br}_{14}\right] @ \mathrm{SiO}_{2}$ & 380 & 550 & 26.67 & 0.01 & 2.83 & 0.10 & 0.95 & 0.89 \\
$\mathrm{ZnO}-\mathrm{Cs}_{2}\left[\mathrm{Mo}_{6} \mathrm{Br}_{14}\right] @ \mathrm{SiO}_{2}$ & 450 & 725 & 58.14 & 0.24 & 14.3 & 0.32 & 1.91 & 0.44 \\
$\mathrm{Cs}_{2}\left[\mathrm{Mo}_{6} \mathrm{Br}_{14}\right] @ \mathrm{SiO}_{2}$ & 340 & 670 & 40 & 0.2 & 1.9 & 0.8 & - & - \\
\hline
\end{tabular}


Submitted to \& Particle Systems Characterization

\section{Table of Contents}

$\mathrm{ZnO}$ nanocrystals and $\mathrm{Mo}_{6}$ clusters are embedded in silica nanoparticles through a modified Stöber process. The resulting materials offer tunable emission properties with a broad emission covering almost all the visible range for an excitation wavelength of $365 \mathrm{~nm}$. The luminescence properties of the nanoparticles remain stable even when they are dispersed in water.

Keyword: metal atom clusters; silica nanoparticles; tunable luminescence; $\mathrm{ZnO}$ nanocrystals

T. Aubert*, N. Nerambourg, N. Saito, H. Haneda, N. Ohashi, M. Mortier, S. Cordier*, and F. Grasset*

Tunable Visible Emission of Luminescent Hybrid Nanoparticles Incorporating Two Complementary Luminophores: $\mathrm{ZnO}$ Nanocrystals and $\left[\mathrm{Mo}_{6} \mathrm{Br}_{14}\right]^{2-}$ Nanosized Cluster Units

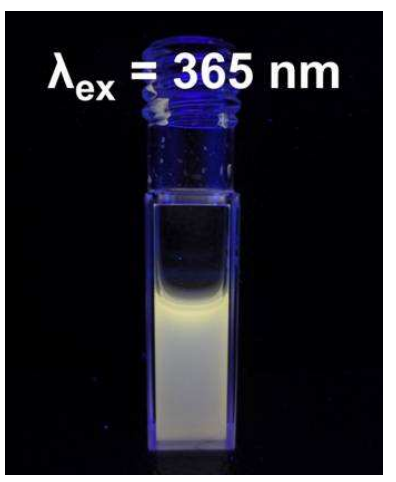

